\title{
Abordagem Histórica da Educação Especial no Brasil
}

\author{
Francisca Marly Moreira da Silval ; Irineide Santos Leandro ${ }^{2}$; \\ Girlândia Pereira Bezerra ${ }^{3}$; Edinalda Ferreira de Lima $^{4}$
}

\begin{abstract}
Resumo: O presente estudo visa discutir os aspectos atinentes à Educação Especial e, neste sentido, a pesquisa objetiva investigar os princípios legais da Educação Especial na Educação brasileira, analisando, ainda, a população elegível para atendimento educacional especializado, os tipos de recursos educacionais especiais e o lócus de atendimento escolar do referido alunado. É importante ressaltar que tais aspectos ainda exigem aclaramento conceitual para que não restem dúvidas quanto às diretrizes da política educacional brasileira a serem seguidas, sendo inegável, entre outras ações, que o atendimento escolar de alunos com necessidades educacionais especiais deve ser universalizado, que os sistemas de ensino precisam responder melhor às demandas de aprendizagem desses alunos, que aos professores deve ser garantida formação continuada. Para essas reflexões buscaremos respaldo teórico em Montoan (2006), Padilha (2001), Skliar (1997), Unesco (2004), entre outros. Caracteriza-se como uma revisão e literatura e, através deste percurso metodológico, aborda as questões históricas que marcam os acontecimentos na educação inclusiva e principalmente os avanços na legislação brasileira.
\end{abstract}

Palavras-chave: Educação Especial. Atendimento Educacional. Legislação Brasileira

\section{Historical Approach to Special Education in Brazil}

\begin{abstract}
The present study aims to discuss the aspects related to Special Education and, in this sense, the research aims to investigate the legal principles of Special Education in Brazilian Education, also analyzing the population eligible for specialized educational services, the types of special educational resources and the locus of school attendance. It is important to emphasize that these aspects still require conceptual clarification so that there is no doubt about the guidelines of the Brazilian educational policy to be followed. Among other things, it is undeniable that the school attendance of students with special educational needs must be universalized, that the systems need to respond better to the learning demands of these students, that teachers should be guaranteed continuing education. For these reflections we will seek theoretical support in Montoan (2006), Padilha (2001), Skliar (1997), Unesco (2004), among others. It is characterized as a review and literature and, through this methodological course, addresses the historical issues that mark the events in inclusive education and especially the advances in Brazilian legislation.
\end{abstract}

Keywords: Special Education, Educational Assistance, Brazilian Legislation

\footnotetext{
${ }^{1}$ Graduada em Pedagogia e Letras, Especialista em Psicopedagogia, em Literatura Brasileira e em Coordenação Pedagógica e Práticas Pedagógicas Interdisciplinares; Mestranda em Ciências da Educação pelo Programa de Pós-Graduação - PPG da Absolute Christian University. E-mail: franmarly@bol.com.br.

${ }^{2}$ Licenciada em Normal Superior e Especialista em Psicopedagogia; Mestranda em Ciências da Educação pelo Programa de PósGraduação - PPG da Absolute Christian University E-mail: irineidesantosleandro@ gmail.com.

${ }^{3}$ Graduação em Pedagogia e Especialização em Metodologia do Ensino Mestranda em Ciências da Educação pelo Programa de PósGraduação - PPG da Absolute Christian University. E-mail: girlandia.cz@ hotmail.com.

${ }^{4}$ Graduada em Pedagogia e Especialista em Psicopedagogia. Mestranda em Ciências da Educação pelo Programa de Pós-Graduação

- PPG da Absolute Christian University. E-mail: edinalda_ferreira@ hotmail.com.
} 


\section{Introdução}

Este estudo discute os aspectos legais da política de educação inclusiva no Brasil, do direito à educação e a concepção de inclusão. Na Constituição 1988 e leis educacionais que apoiam a necessidade de reconstruir a escola objetivando mudança, transformação e inovação de uma educação de qualidade e aberta as diferenças e, neste contexto, levantar discussões a respeito do educar na diversidade e, nesse sentido, atuar na construção gradativa dos conhecimentos sobre a educação inclusiva, ressaltando ainda, que a legislação brasileira determina como direito de todos o acesso ao ensino regular, público e gratuito. Todavia, essa garantia nem sempre é real, visto que nos deparamos, diariamente, com situações nas quais essas garantias não saem do papel, situação pela qual percebemos as barreiras na construção de uma educação inclusiva.

O trabalho tem como objetivo investigar na Educação Especial seus princípios legais na Educação, os quais iremos explicitar apontando conceitos e concepções referentes à Educação Especial. O referencial teórico é de importância fundamental para a realização deste trabalho, para o qual foram analisados como base no referencial teórico as contribuições de autores como: Mazzotta (1996), Montoan (2006), Padilha (2001), Skliar (1997), Unesco (2004), entre outros.

Considerando as bases argumentativas que norteiam este estudo, também discutiremos a relevância do processo formativo do professor para atuar em salas de recursos multifuncional, considerando a necessidade do atendimento a crianças com necessidade especiais. É necessário esclarecer que embora ocorram avanços no processo de aprendizagem e o professor esteja envolvido em processos de inclusão e modelos de atendimento para o acompanhamento pedagógico do aluno com necessidades educativas especiais, essas ações, embora relevantes, ainda não foram suficientes do ponto de vista do atendimento desse grande grupo e alunos. Portanto, o professor inclusivo é aquele que promove mudanças na organização das interações dos alunos, articula o compartilhar da aprendizagem em duplas, valorizar os momentos de trocas e perguntas num processo de aprendizagem inacabável.

Por fim, este estudo é uma fonte bibliográfica de grande relevância na comunidade acadêmica para outros profissionais da educação perante o estudo realizado, visto que oferece suporte suficiente para discussões e, por tal, contribuem para o fomento do debate sobre a Educação Especial.

263 Id on Line Rev. Mult. Psic. V.13, N. 45, p. 262-275, 2019 - ISSN 1981-1179 Edição eletrônica em http://idonline.emnuvens.com.br/id 


\title{
Conceito de Educação Inclusiva
}

No Brasil, a Política de Educação Inclusiva é uma temática atual, mas que ainda está distante da realidade de muitas pessoas que dela necessitam. Antes das atuais políticas inclusivas, a pessoa com deficiência era tratada como doente, sendo direcionadas ao tratamento clínico. Ademais, naquele contexto, o indivíduo com deficiência era tido como sujeito "louco" e era direcionado a clínicas psiquiátricas. E foi a partir daí que os médicos perceberam que a pessoa com deficiência tinha a necessidade e a capacidade de ingressar no ensino escolar. Como destacam os autores Glat e Fernandes (2005, p. 01):

\begin{abstract}
A Educação Especial se constituiu originalmente como campo de saber e área de atuação a partir de um modelo médico ou clínico. Embora hoje bastante criticado, é preciso resgatar que, como lembra Fernandes (1999), os médicos foram os primeiros que despertaram para a necessidade de escolarização dessa clientela que se encontrava 'misturada' nos hospitais psiquiátricos, sem distinção de idade, principalmente no caso da deficiência mental. Sob esse enfoque, a deficiência era entendida como uma doença crônica, e todo o atendimento prestado a essa clientela, mesmo quando envolvia a área educacional era considerado pelo viés terapêutico. A avaliação e identificação eram pautadas em exames médicos e psicológicos com ênfase nos testes projetivos e de inteligência, rígida classificação etiológica.
\end{abstract}

Para Margarezi (2010), a Política de Educação no Brasil foi permeada por interesses das classes dominantes, contexto que sempre privilegiou as classes dominantes em detrimento da trabalhadora para o acesso a uma educação de qualidade. Por esse limiar e delimitado pelas mesmas questões governamentais, a educação especial no país é marcada por práticas assistencialistas e filantrópicas, nas quais grande parte da população ficou à mercê de mecanismos isolados e dependentes de instituições públicas, privadas e filantrópicas.

Nesse contexto, a educação inclusiva possibilita às pessoas que tem algum tipo de deficiência a possibilidade de conviver em um espaço educacional com outras pessoas sem deficiências. Este fato proporciona a inclusão social e a formação educacional dessas pessoas que irão ter capacidade de aprender, embora em tempo e de forma diferente, respeitando-se as peculiaridades de cada uma.

Mazzota (2010 apud MARGAREZI, p. 15) aponta três grandes períodos da trajetória da educação especial no Brasil. Segundo a autora, a primeira ocorreu entre os anos de 1954 e 1956, nas quais as iniciativas eram oficiais e particularmente isoladas, pois atendiam, de

264 Id on Line Rev. Mult. Psic. V.13, N. 45, p. 262-275, 2019 - ISSN 1981-1179 Edição eletrônica em http://idonline.emnuvens.com.br/id 
maneira avançada, os diferentes tipos de deficiência, momento no qual se começa a revelar uma tendência de indicação da educação inclusiva com a criação do Imperial Instituto dos Meninos Cegos em 1854.

O segundo período, de acordo com o autor, começa com o avanço das iniciativas públicas que passam a desenvolver campanhas e estruturar órgãos de acordo com as especificidades para cada deficiência. Assim, o período de 1957 até 1993 marca um importante avanço, pois dispõe de espaço para a organização da educação inclusiva no âmbito nacional.

Mas, é no terceiro período, identificado a partir da Lei de Diretrizes e Bases da Educação Nacional (LDB), Lei 9394/96 é que há o reconhecimento da educação especial como uma política de educação. Esse momento passa a promover uma regulação da educação para a pessoa com deficiência, propiciando que as escolas públicas ofertassem as condições necessárias para receber esses estudantes, com condições para muito além da estrutura física, mas com subsídios pedagógicos para a educação especial.

Cabe salientar, também, que o Estado deveria ser o regulador das Políticas Sociais, no entanto, é permeado por interesses de classe e, por tal, foge da neutralidade para servir predominantemente a uma classe dominante (BOSCHETTI, 2010). Neste contexto, a educação como direito fundamental caracteriza-se como uma utopia para a transformação da sociedade, visto que não é garantida de maneira igualitária.

Pelos aspectos ora apresentados, é nítido que a Política de Educação Inclusiva não é efetivada como uma política que garante à pessoa com deficiência uma educação de qualidade, visto que a acessibilidade nos espaços públicos e nas escolas é quase inexistente e, quando existem, não possuem estrutura adequada.

Outro aspecto as ser destacado é que a educação inclusiva, muitas vezes, é imposta sem planejamento eficaz e impõe às escolas o dever de incluir as crianças que possuem alguma deficiência, sem lhes fornecer subsídios que possibilitem um trabalho que seja efetivo e que gere resultados satisfatórios.

Acerca desse direcionamento, na Declaração Salamanca realizada na Espanha entre 7 a 10 de junho de 1994, os delegados da Conferência Mundial de Educação Especial, representando 88 países e 25 organizações internacionais, reafirmaram o compromisso com a educação para todos com necessidades especiais dentro do ensino regular. Neste documento proclamaram que

265 Id on Line Rev. Mult. Psic. V.13, N. 45, p. 262-275, 2019 - ISSN 1981-1179 Edição eletrônica em http://idonline.emnuvens.com.br/id 
[...] toda criança tem direito fundamental à educação, e deve ser dada a oportunidade de atingir e manter o nível adequado de aprendizagem, • toda criança possui características, interesses, habilidades e necessidades de aprendizagem que são únicas, sistemas educacionais deveriam ser designados e programas educacionais deveriam ser implementados no sentido de se levar em conta a vasta diversidade de tais características e necessidades, aqueles com necessidades educacionais especiais devem ter acesso à escola regular, que deveria acomodá-los dentro de uma Pedagogia centrada na criança, capaz de satisfazer a tais necessidades, escolas regulares que possuam tal orientação inclusiva constituem os meios mais eficazes de combater atitudes discriminatórias criando-se comunidades acolhedoras, construindo uma sociedade inclusiva e alcançando educação para todos; além disso, tais escolas proveem uma educação efetiva à maioria das crianças e aprimoram a eficiência e, em última instância, o custo da eficácia de todo o sistema educacional (DECLARAÇÃO SALAMANCA, 1994).

Decorrente da importância das determinações estabelecidas em Salamanca, no Brasil, outro documento legal de suma importância para a inclusão da pessoa com deficiência no ensino regular foi a Lei de Diretrizes e Bases da Educação Nacional - LDB de 1996, visto que, em suas determinações aborda particularidades da educação especial através da Lei No 9394/96, destacando que,

\begin{abstract}
Art. 58. Entende-se por educação especial, para os efeitos desta Lei, a modalidade de educação escolar, oferecida preferencialmente na rede regular de ensino, para educandos portadores ${ }^{5}$ de necessidades especiais. $\S 1^{\circ}$ Haverá, quando necessário, serviços de apoio especializado, na escola regular, para atender as peculiaridades da clientela de educação especial. $\S 2^{\circ} \mathrm{O}$ atendimento educacional será feito em classes, escolas ou serviços especializados, sempre que, em função das condições específicas dos alunos, não for possível a sua integração nas classes comuns do ensino regular. $\S^{\circ} \mathrm{A}$ oferta da educação especial, dever constitucional do Estado, tem início na faixa etária de zero a seis anos, durante a educação infantil [...]. (BRASIL, 1996, p.55)
\end{abstract}

Considerando a vasta legislação em prol da Educação Especial apontada Margarezi (2010), a autora ressalta que há uma contradição no modelo de educação inclusiva, pois possibilita, segundo a Lei, uma grande mudança na realidade da pessoa com deficiência, em oposição ao Estado neoliberal que garante a precarização das escolas e do ensino.

\footnotetext{
5 [...] Os movimentos mundiais de pessoas com deficiência, incluindo os do Brasil, já fecharam a questão: querem ser chamados de "pessoas com deficiência", em todos os idiomas. Esse termo faz parte do texto da Convenção sobre os Direitos das Pessoas com Deficiência, adotado pela ONU em 2006, ratificado com equivalência de emenda constitucional no Brasil através do Decreto Legislativo $\mathrm{n}^{\circ} 186$ e promulgado por meio do Decreto $\mathrm{n}^{\circ}$ 6.949 Site externo, em 2009. Disponível em: http://diversa.org.br/artigos/como-chamar-pessoas-que-tem-deficiencia/ Acesso: 01/08/2017 às 21h47min.
}

266 Id on Line Rev. Mult. Psic. V.13, N. 45, p. 262-275, 2019 - ISSN 1981-1179 Edição eletrônica em http://idonline.emnuvens.com.br/id 
Assim, percebe-se que há um modelo de educação inclusiva no qual se amplia a participação nos espaços de ensino regular, apresenta-se como uma proposta salvadora na educação inclusiva que proporciona mudanças na realidade das pessoas com deficiência e tem como objetivo o crescimento e a satisfação pessoal e a integração social.

Entretanto, sua implementação encontra contradições na sociedade neoliberal, na qual o Estado propicia o sucateamento das escolas, a desregulamentação das condições de trabalho e dos salários, promove a desmobilização das categorias profissionais, enfim, sucateamento que influencia o fracasso escolar, a repetência e, consequentemente, a evasão.

Rodrigues; Lima-Rodrigues (2011) definem educação inclusiva como uma reforma educacional, pois abrange diferentes níveis de mudanças. Para os autores, o objetivo da educação inclusiva não se limita ao acesso de alunos com necessidades especiais ao ensino regular, pois se refere a renovações mais profundas, trazendo novos valores e realidade de todo o sistema de ensino atualmente desenvolvido.

Neste contexto, Santana (2005) destaca, ainda, a relevância da formação de docente com base em uma qualificação que não se restrinja a cursos eventuais, mas transcenda a programas de capacitação que sejam realizados frequentemente, através dos quais os educadores precisam ser ajudados a buscar, refletir sua prática e compreender a relação entre o ensino e a aprendizagem.

Por esse limiar, os docentes devem ser considerados como pontos importantes no processo de aprendizagem dos alunos, sejam eles com alguma deficiência ou não. Por outro lado, professores mal remunerados, pouco reconhecidos, cansados devido as extensas jornadas de trabalho impostas pela busca de melhores condições de vida e inseridos em múltiplos empregos desmotivam os educadores a resgatar o que há de melhor em cada educando e, neste sentido, de transformar o momento de aprendizagem num momento prazeroso e edificante.

Vale ressaltar, ainda, que a Política de Educação Inclusiva assegura, com base na Constituição Federal - CFB de 1988 que:

A Constituição Federal de 1988 traz como um dos seus objetivos fundamentais
'promover o bem de todos, sem preconceitos de origem, raça, sexo, cor, idade e
quaisquer outras formas de discriminação' (art. $3^{\circ}$, inciso IV). Define, no artigo
205, a educação como um direito de todos, garantindo o pleno desenvolvimento
da pessoa, o exercício da cidadania e a qualificação para o trabalho. No seu artigo
206, inciso I, estabelece a 'igualdade de condições de acesso e permanência na
escola' como um dos princípios para o ensino e garante como dever do Estado, a 
oferta do atendimento educacional especializado, preferencialmente na rede regular de ensino (art. 208). (BRASIL, 2007, p. 02)

Nascimento; Silva; Martins (2014) ressaltam que a educação inclusiva encontra grandes dificuldades como a falta de pessoas capacitadas. Umas delas e marcada pelas frustrações de professores por falta de conhecimento para lidar com alunos com deficiência, além dos preconceitos e estereótipos a eles conduzidos.

Destacam, também, que é preciso que a escola juntamente com a família desempenhe um papel complementar no processo de socialização desses alunos e que, para isso, precisa que haja um planejamento de ações que sirvam de apoio e tenham uma estrutura necessária para que se consolidem uma educação de qualidade.

Ainda vista como um grande empecilho, a Educação Inclusiva é um desafio a ser enfrentado mesmo diante das mudanças de paradigmas educacionais, pois não se trata apenas de inserir estudantes com necessidades especiais em salas regulares, mas também, instituir relações que possam favorecer atendimento igualitário entre alunos com necessidades educacionais especiais e os demais, para que, de fato, a educação inclusiva se efetive, e que todos se sintam incluídos no ambiente escolar e nos demais espaços. (SOUTO; LIMA; PEREIRA; FARIAS, 2014).

Outro fator que pode ser mencionando é que a educação inclusiva não deve ser banalizada e sim fomentada como uma ferramenta preciosa de inclusão e conhecimento mas, para isso ocorrer a contento, devemos investir em mais estrutura nas escolas, na melhor formação dos educadores em ensino inclusivo, sensibilizar a escola no sentido de entender que cada aluno tem seu modo de aprender, buscar novos métodos de ensino, que realmente inclua todos no processo de ensino aprendizagem.

Para Laplane (2006), a sociedade no geral é caracterizada como uma sociedade excludente em todas as esferas, nas quais as relações são permeadas pelo individualismo, competitividade, seja no mercado de trabalho, na sociedade civil, na justiça. Laplane (2006) analisa, ainda, a política de educação inclusiva dentro das transformações do modo de produção capitalista.

Os educadores, na educação inclusiva, também possuem um papel fundamental em incluir os alunos nas atividades em grupos e de explorar as possibilidades e potenciais que cada discente pode trazer para sala de aula. O papel do professor no ensino inclusivo é desafiador e 
deve ser vivido com perseverança, adaptando-se à realidade, às limitações e, ao mesmo tempo, fazendo com que os alunos transponham essas limitações e galguem por conquistas maiores, pois o conhecimento é mutável e deve ser compreendido como algo que aproxima.

Ao mesmo tempo em que a política de educação inclusiva trás a ideia de integralidade aos estudantes com deficiência, pode romper com os paradigmas do sistema e proporcionar maior competitividade no mercado de trabalho, pois agora a preocupação no âmbito da educação inclusiva é o desempenho do currículo.

Ademais, a Educação Inclusiva enfrenta diversas e grandes dificuldades, a exemplo da falta de profissionais capacitados para trabalhar na área, a estrutura física das escolas e equipamentos, frustrações de professores por não serem capacitados e também os preconceitos sofridos. Por isso, é preciso que haja uma política pública que garanta o desempenho das escolas e as pessoas envolvidas que fornecem apoio e estrutura necessária para que a educação inclusiva.

\section{Atendimento à Pessoa com Deficiência}

A Lei $n^{\circ}$ 13.146/15 institui a Lei Brasileira de Inclusão da Pessoa com Deficiência (Estatuto da Pessoa com Deficiência) e destina-se a promover e assegurar condições de igualdade, de direitos e de liberdade, buscando a cidadania e a inclusão social dos indivíduos. De acordo com o Estatuto da Pessoa com Deficiência, é considerada pessoa com deficiência:

Art. 2o Considera-se pessoa com deficiência aquela que tem impedimento de longo prazo de natureza física, mental, intelectual ou sensorial, o qual, em interação com uma ou mais barreiras, pode obstruir sua participação plena e efetiva na sociedade em igualdade de condições com as demais pessoas. (BRASIL, 2015, p. 8 - 9)

Pelo exposto, entende-se que as limitações de cunho físico, mental ou intelectual podem ser enfrentadas e vencidas por todos, para isso a pessoa com deficiência precisa de apoio e a escola se torna parceira fundamental no processo de enfrentamento e inclusão desses alunos na vida escolar e na sociedade.

A Convenção sobre os Direitos das Pessoas com Deficiência diz que esses sujeitos são como qualquer outra, e que a deficiência é apenas uma característica da condição humana. 


\begin{abstract}
Pessoas com deficiência são, antes de mais nada, PESSOAS. Pessoas como quaisquer outras, com protagonismos, peculiaridades, contradições e singularidades. Pessoas que lutam por seus direitos, que valorizam o respeito pela dignidade, pela autonomia individual, pela plena e efetiva participação e inclusão na sociedade e pela igualdade de oportunidades, evidenciando, portanto, que a deficiência é apenas mais uma característica da condição humana. (Convenção sobre os Direitos das Pessoas com Deficiência, 2011, p.12).
\end{abstract}

Historicamente, as pessoas com deficiência começam a ser acolhidas pela Igreja Católica, sob o prisma da realização de atos de caridade baseados no sentimento de pena pelas pessoas com deficiência e como uma maneira de agradecimento e dever a Deus pela normalidade dos fiéis não deficientes. Nesse contexto, a pessoa com deficiência deixa de ser um objeto ou animal e assume a condição humana, mas de forma dependente ou de segunda categoria (FEIJÓ; PINHEIRO, 2011).

A partir desse contexto, mesmo sendo considerados de segunda categoria, emergem as práticas assistencialistas que, por sua vez, representaram um grande avanço. No entanto, trazem consequências. Inicialmente, quando se deu a propagação de que a pessoa com deficiência deveria ser isolada do mundo, ou seja, afastada da sociedade através do encarceramento, fato que fez surgirem os hospícios. A segunda, é o reforço de que a pessoa com deficiência tinha uma deformidade e deveria receber cuidados da caridade cristã, sob o fundamento de que a perfeição do ser era o correto. (FEIJÓ; PINHEIRO, 2011).

Vale pontuar, que os hospícios muitas vezes pioravam a condição emocional das pessoas que estavam internadas. Além disso, a segregação social, aliada ao distanciamento de familiares, fragilizava ainda mais o indivíduo que possuía algum tipo de deficiência. Atualmente, compreende-se que o convívio social o acolhimento das famílias é um dos melhores tratamentos para as pessoas que sofrem de algum transtorno psíquico.

É importante compreender que há contradições do atual dilema em volta da inclusão, visto que muitas pessoas declaradas como deficientes, de alguma maneira, viveram no período bárbaro e recebiam algum tipo de instrução educacional, mesmo sendo de forma não formal, ainda que não se possa comparar com a oferta formal de educação da sociedade atual.

Para apreender esse movimento, é preciso compreender as alterações ocorridas com o final da comuna primitiva (Bueno, 1993) e mudanças da sociedade, com o surgimento da sociedade de classes, que configura a expropriação de uma classe pela a outra. É fundamental evidenciar que as pessoas com deficiência, assim como os demais trabalhadores, eram 
instruídos aos interesses da classe dominante, os indivíduos com alguma deficiência subsistem em condições mais danosas que os escravos, os servos e os proletários, mesmo que se reconheça que as condicionalidades sempre tinham as piores condições de trabalho.

Ainda para justificar o não aproveitamento laboral das pessoas com deficiência, criaram-se histórias de discriminação e rotulação para tratar e nomear esses sujeitos (CARVALHO; TURECK, 2014).

Através de muitos debates, os movimentos mundiais de pessoas com deficiência, incluindo o Brasil, chegaram ao termo " pessoa com deficiência” para todos os idiomas. Essa expressão faz parte do texto da Convenção Internacional para Proteção dos Direitos e Dignidade das Pessoas com Deficiência (SASSAKI, 2002).

Com o surgimento do sistema capitalista, propicia-se uma integração, no que diz respeito à igualdade de direitos. Olney Queiroz Assis e Lafayette Pozzoli (2005)

\footnotetext{
[...] reforçam a ideia de que é com a sociedade industrial e, consequentemente, com o Estado moderno, que se desenvolverá uma nova estratégia sobre o corpo humano. Agora, não mais para expô-lo ou mutilá-lo, mas para aprimorá-lo, recuperá-lo e adestrá-lo. E é justamente nessa época, pós 1789, que vários inventos foram criados para propiciar meios de trabalho e locomoção às pessoas com deficiência, tais como a cadeira de rodas, as bengalas, os bastões, as muletas, os coletes, as próteses, as marcas, os veículos adaptados, as camas móveis etc. (FONSECA, 1997). (FEIJÓ; PINHEIRO, 2011 p.6)
}

Carvalho; Tureck (2014) apontam, que de acordo com Vigotski (1997), o desenvolvimento psíquico da pessoa com deficiência pode ocorrer de maneira diferente das crianças ditas "normais", entretanto pode desenvolver-se de forma satisfatória. Destacam ainda a luta pela educação formal desses indivíduos, principalmente após a Segunda Guerra Mundial, quando as pessoas com deficiência passam à condição de deficiente diante da sociedade como os soldados e outras vítimas civis.

Segundo Alves (2016), a Educação Especial no município surge da mesma maneira no Brasil, das instituições especializadas. A APAE (Associação de Pais e Amigos dos Excepcionais) se molda a partir dos avanços constitucionais e, a partir daí, se inicia o processo de implementação das salas de recursos multiprofissionais, equipadas adequadamente às necessidades dos alunos com deficiência.

Perante a difícil realidade, cabe a todas denunciar o caráter do Estado brasileiro com posturas neoliberais, ao não cumprir as suas responsabilidades, no que diz respeito à garantia 
de aspectos estruturantes para a educação das pessoas com deficiência, pois aliena o debate, como já faz nas outras áreas da educação (CARVALHO; TURECK, 2014).

Ressaltamos que a educação é uma das formas mais eficientes de formar cidadãos para a vida, de formar pessoas mais sensíveis, humanas e que possam enxergar além dos limites, ouvir mais do que se diz e sentir com mais fervor, a educação edifica e transforma vidas, muda contextos e se consolida em seres tão subjetivos como os humanos.

Neste contexto, a educação inclusiva é mais desafiadora porque estende as portas do conhecimento a pessoas limitadas. Porém, esquecemos que os limites são transponíveis quando os deficientes físicos querem ir pra escola, mas não conseguem entrar e nem sequer se locomover dentro das instalações, as estruturas físicas sucateadas tornam o ambiente hostil e perigoso para o aluno.

Por outro lado, os alunos com algum tipo de transtorno mental se veem sufocados ao terem que estudar com materiais didáticos que não atendem as suas peculiaridades. É como se mais valesse estarem ali "inclusos" a estarem realmente aprendendo e crescendo. Tudo isso é reflexo da ausência de compreensão das autoridades políticas em buscar edificar uma escola de qualidade para todos com estrutura física que atenda às necessidades, com professores capacitados e treinados frequentemente para atende com afinco as necessidades dos alunos.

Posto as dificuldades no processo de construção de uma política de educação inclusiva que consiga garantir o acesso a pessoa com deficiência com qualidade, estamos trilhando no caminho certo, apesar dos diversos obstáculos que precisam ser para que se tenha uma educação transformadora, respeitando as diversidades dos sujeitos.

Nesse sentido, é de suma importância fomentar as discussões acerca da educação inclusiva, com professores (as), estudantes, profissionais, pais e a comunidade em geral, para buscar romper barreiras e criar um ambiente que seja pautado na consciência e no respeito dos envolvidos neste processo.

Outro ponto fundamental é a compreensão do processo de inclusão com maior participação social da pessoa com deficiência. Investir em pesquisas, em recursos materiais e implementar ações que assegurem a formação continuada de professores, para oferecer melhores condições de atendimento educacional aos alunos com deficiência é uma medida que pode colaborar para a mudança da realidade atual. 


\section{Considerações Finais}

Tendo em vista o resumo histórico das mudanças que ocorreram com a concepção sobre Educação Especial, percebe-se que ocorreram mudanças significativas em considerar pessoas com necessidades educativas especiais, além das alterações geradas acerca da concepção de diversidade e deficiência, da Antiguidade e na Idade Média ao período entre o século XVI e o século XIX, e na contemporaneidade. Esse entremeio histórico levou-nos a considerar a percepção social sobre a integração da pessoa ao sistema educacional como fundamental ao sistema educacional, em especial e inclusiva.

Neste contexto, é de extrema relevância retomar alguns atos normativos na regulamentação das ações educativas para as pessoas com necessidades educativas especiais, percebemos a legislação e, de uma forma geral, percebemos que todas concordam com o pensar sobre a educação especial e inclusiva como um processo estritamente integrado à sociedade e à educação básica regular.

Ao rever parte da história da evolução do conceito sobre educação inclusiva até XVIII, é perceptível a necessidade de uma nova definição para ser possível uma educação integral e mais ampla do sujeito, invalidando assim o termo estigmatizado, deficiência, reforçado pelo termo preconceito, pela forma depreciativa de tratar pessoas com necessidade especiais.

No tocante à educação especial, bem como a população elegível para atendimento educacional especializado, os tipos de recursos educacionais especiais e o lócus de atendimento escolar do referido alunado, compreende-se que há a necessidade aclaramento conceitual para que não restem dúvidas quanto às diretrizes da política educacional brasileira a serem seguidas.

Ademais, é inegável, entre outras ações, que o atendimento escolar de alunos com necessidades educacionais especiais deva ser universalizado, que os sistemas de ensino precisam responder melhor às demandas de aprendizagem desses alunos e que aos professores seja garantido formação continuada.

É essencial que o professor tenha clareza sobre o que são objetivos de ensino para planejar ações e atividades pedagógicas na sala multifuncional, portanto, os objetivos do ensino e aprendizagem, melhor elaborados, estão direcionados à realidade em relação a qual o aluno necessitará eliminar as barreiras cognitivas no seu desenvolvimento. 
É relevante destacamos que o professor tenha clareza sobre a sua prática em uma sala de aula multifuncional, utilizando recursos necessários para atendimento de crianças e jovens que apresentam as dificuldade no processo de ensino e aprendizagem.

Enfim, enfatizamos a importância de se ter maior conhecimento teórico acerca da prática de educação especial, sempre buscando novos saberes para trabalhar em sala de aula, contribuindo com desempenho e vida escolar dos alunos matriculados na escola.

\section{Referências}

BRASIL, Lei de Diretrizes e B. Lei no 9.394/96, de 20 de dezembro de 1996

Ministério da Educação. Secretaria de Educação Especial. Educação inclusiva: atendimento educacional especializado para a Deficiência Mental. Brasília, 2005.

. Secretaria da Educação Especial. Estratégias e orientações pedagógicas para a educação de crianças com necessidades educacionais especiais: Introdução. Brasília: 2002.

\section{_. Resolução CNE/CEB 2/2001. Institui Diretrizes Nacionais para a Educação Especial na Educação Básica. Disponível em: <http://portal.mec.gov. br/cne/arquivos/pdf/CEB0201.pdf>. Acesso em: 18 abr. 2018.}

. Ministério da Educação e do Desporto. Conselho Nacional de Educação. Parecer $\mathrm{CNE} / \mathrm{CEB}$ 4/98. Diretrizes Curriculares Nacionais para o Ensino Fundamental. Disponível em: < http://portal.mec.gov.br/cne/arquivos/pdf/PCB04_1998.pdf>. Acesso em: 30 abr. 2018.

Constituição (1988). Constituição da República Federativa do Brasil. Brasília, DF: Senado Federal: Centro Gráfico, 1988.

Lei n. 12.796, de 4 de abril de 2013: altera a Lei n. 9.394 de 20 de dezembro de 1996, que estabelece as diretrizes e bases da educação nacional, para dispor sobre a formação dos profissionais da educação e dar outras providências. Brasília: Planalto Central, 2013.

BORGES, Marisa; A Política Educacional nos anos de 1980 E 1990: Qual a proposta de democratização da Gestão Escolar? ATOS DE PESQUISA EM EDUCAÇÃO - PPGE/ME FURB ISSN 1809-0354, v. 7, n. 1, p. 143-174, jan./abr. 2012

BOSCHETTI, I. Os custos da crise para a política social. In: BOSCHETTI, I; BEHRING, E. R; SANTOS, S. M. M.; MIOTO, R. C. T. (Orgs.). Capitalismo em crise: Política social e direitos. São Paulo, Cortez, 2010.

DECLARAÇÃO DE SALAMANCA e Linha de Ação sobre necessidades Educativas Especiais. Brasília: CORDE, 1994. 
GLAT, Rosana; MASCARENHAS, Edicléa. Da Educação Segregada à Educação Inclusiva: uma Breve Reflexão sobre os Paradigmas Educacionais no Contexto da Educação Especial Brasileira. Artigo publicado na Revista Inclusão nº 1, 2005, MEC/ SEESP.

MARGAREZI; Andreia Leticia ,Educação inclusiva e as possibilidades de intervenção para o assistente social, SER/IH da Universidade de Brasília (2010)

MONTOAN, Maria Teresa Eglér. Inclusão Escolar: pontos e contrapontos. São Paulo: Summus, 2006.

ONU,Declaração Universal dos direitos humanos. Disponível em:http://www.onu.org.br/img/2014/09/DUDH.pdf UNIC / Rio / 005 - Agosto 2018

SASSAKI, Romeu K. Inclusão: construindo uma sociedade para todos. Rio de Janeiro: Editora WVA, 2002

VIEIRA; Givanilda Márcia. Educação inclusiva no brasil: do contexto histórico à contemporaneidade (2012).

Como citar este artigo (Formato ABNT):

SILVA, Francisca Marly Moreira da; LEANDRO, Irineide Santos; BEZERRA, Girlândia Pereira; LIMA, Edinalda Ferreira de. Abordagem Histórica da Educação Especial no Brasil. Id on Line Rev.Mult. Psic., 2019, vol.13, n.45, p. 262-275. ISSN: 1981-1179.

Recebido: 07/04/2019

Aceito 11/04/2019 